\title{
Notes on the Life History of Gammarus cheureuxi
}

\author{
By
}

E. W. Sexton and Annie Matthews, M.Sc.

\section{INTRODUCTION.}

THE present paper is the outcome of an investigation made on a species of Gammarus inhabiting both fresh and brackish water (4, p. 657). As this species (G. zaddachi) seemed to show a marked variation in appearance according to its environment, we instituted experiments in the Laboratory at Plymouth on G. chevreuxi to see if a similar variation in appearance could be brought about by varying the degree of salinity of the water in which the animals lived.

It would have been impossible to have obtained any measure of success without the kind co-operation of Dr. Allen, and we wish here to acknowledge our indebtedness to him, and to the various members of the staff for their continual and willing help.

Our ultimate object, which is to establish if possible a variation in the appearance of a given species by altering its environment, has had to stand over for a time, until other more pressing problems were settled. The first of these was how to ensure a constant supply of healthy animals, able to live and breed under Laboratory conditions, and the next was to find if it were possible to bring them to live in fresh water and in sea-water. In both of these experiments we have succeeded far better than we anticipated. We have now (January, 1913) the young of the fifth generation, bred from the animals captured in June; and, after some three months' gradual altering of the original water, we have some individuals living and breeding in absolutely fresh water, while others of the same stock are living and breeding in pure sea-water. Other problems in the life history have still to be worked out, this paper being intended only as a summary of the work as far as we have gone. Some of our conclusions will no doubt need revision later.

It must be remembered that the results here given are all obtained under artificial conditions. If it were simply a question of multiplying generations the conditions could have been made more like the natural 
surroundings, with stones, and plenty of mud and dirt provided for the shelter the animals seek when they moult, etc. Our method of work, however, necessitated daily observations being taken without unnecessary disturbance, and the bowls had therefore to be kept in the light, free from dirt and dust, and with only just sufficient ulva for food and not enough to provide a hiding-place.

We chose for our experiments the brackish-water Gammarus chevreusi, as being easily obtainable in the neighbourhood. It occurs in the ditches draining Chelson Meadow (see previous paper).

\section{GENERAL METHODS.}

We brought our first specimens to the Laboratory on June 4 of last year (1912), together with some of the water, ulva, and the isopod Sphaeroma serratum, from the same ditch.

The next day two mated pairs were taken, and daily observations commenced. We kept these in jars partly covered to exclude dust, but a sufficient supply of air was ensured by a continuous bubbling of air through the water. We have found since that this is not essential, provided enough air can be supplied in some other way, such, for instance, as exposing a large surface of water to the air. In this way several broods have done well in large crystallizing dishes, about twelve inches across and two-thirds full of water, dust being excluded as in the jars. We consider, however, that we get better results, with the older animals at any rate, when the water is aerated.

With regard to the young, experience has shown us that the best method of observing them through their various stages to sexual maturity, and of obtaining their moults as they are cast, is to place each individual in a separate finger-bowl, half full of water, and almost wholly covered with a glass plate. The water is aerated once a day with a pipette, and a little ulva is given for food.

All the dishes and jars have been kept in ordinary diffused daylight, not protected in any way.

The temperature in the Laboratory in summer probably does not differ much from that in the ditches, but in winter it is considerably higher. It varies through a number of degrees at different times of the day and on different days. The animals, however, appear but little affected by this variation. The only point we have noticed is that the rate of development and the time of reaching sexual maturity are retarded by a lower temperature. In the Laboratory from October to December the temperature of the water in the moult-bowls varied between $10^{\circ}-16^{\circ} \mathrm{C}$.; in another room not artificially heated the range 
was from $4^{\circ}-10^{\circ} \mathrm{C}$. during the same period. In order to test the difference, if any, in the rate of moulting, a brood was divided, half being kept in the Laboratory and half in the other room, and it was found that some of the young took twice as long over their first moult in the colder place-in fact, some of those in the Laboratory had accomplished a second moult before all the young in the other room had finished their first.

The main food is ulva, supplemented by enteromorpha, and the rotting leaves of oak, beech, and sycamore. Certain kinds of animal food are eagerly taken, such as Sphaeroma serratum from the ditches in all stages of putrefaction, but this is a diet we give sparingly for fear of fouling the water.

Occasionally healthy males will attack and devour weak or sickly females, but they have not been seen eating dead ones. The animals will tear up their cast skins or "moults," and if these are not removed within, say, twenty-four hours, they will disappear completely. The inference is that they are eaten, and we feel sure this inference is correct, although we have no direct proof. It is certainly the case in other genera-two Jassa, for instance, were actually watched in the Laboratory devouring their skins immediately after ecdysis; and again, we have never found any torn pieces of a moult that has disappeared in the dirt pipetted daily out of the bowls.

Both male and female feed during the carrying period of the mating -not only cropping the ulva while resting on it, but holding pieces with their gnathopods while swimming. The young feed while in the incubatory pouch; their intestines are full when they emerge.

\section{REPRODUCTION.}

The conclusions arrived at by Holmes (3) and Embody (2) on the mating of Amphipods are, as we understand, as follows:-(1) that neither sight nor smell is concerned in the mating of a pair; (2) that they meet accidentally; and (3) that the female is wholly passive throughout, and indeed that the male recognizes her as a female by this passivity. Our results, as far as we have gone, indicate on the contrary that mating is not one-sided but mutual, and that a female when in the right physiological condition will at times seek the male, and, on the other hand, when not in this condition will actively resist him. The meeting of the sexes in the first place seems accidental, but the one certainly appreciates the presence of the other by the touching of the antennae. The antennae are provided with highly developed sensory organs, in which the olfactory sense may or may not be 
located, but we feel certain that in our species the animals always employ the antennae in meeting others, and in recognizing their own species.

Sexual maturity in both sexes is attained when the animals are about half grown. The time they take in reaching maturity varies greatly, but the cause of such variation is not yet known. The young produced in summer appear to become mature in much less time than those hatched later, but this cannot be laid down as a rule, as there is evidently some other potent factor at work besides temperature. The first brood of Pair I was extruded on June 19th and reached maturity on July 25 th, i.e. in thirty-six days. Sometimes, however, a later brood will reach maturity before an earlier; for instance, Brood II of Pair II, extruded July 4th, did not reach maturity till September 4th, a period of sixty-two days, while Brood IV of the same pair, extruded July 29 th, became mature on September 9 th, only forty-two days.

The male takes the female when their respective gonads are becoming mature and carries her sometimes for days before mating takes place. This occurs once a fortnight with the female, so that, in ideal conditions, twenty-six broods could be produced annually. This would imply that breeding continues throughout the year, and such we believe to be the case, at any rate in a mild climate like Plymouth. It has gone on uninterruptedly in our jars during the seven months we have been working, from early in June to mid-January, and breeding pairs are still found in the ditches in Chelson Meadow.

The male, on the other hand, seems to have no regular mating period, but can fertilize a succession of females with an occasional period of rest. One young male, which became sexually mature on September 28 th at the age of fifty-two days, by October 1st had fertilized the three females in the same jar. An interesting point to note is that the last female had only two eggs, and these were thrown off the next day, which may have been due to the fact that the eggs were not properly fertilized, and also suggests that the number of eggs extruded may bear some relation to the condition of the male. Again, in Brood I of Pair I a male and a female became mature in thirty-six days; four days later four other females were fertilized by this male and another, and again the last females mated had a small number of eggs, five and seven respectively, while the first female had eighteen. How many times in succession a male can mate we do not yet know, because we have never had a succession of females in the right condition. If a male is placed in a dish with several females whose eggs are at different stages of development, he chooses one with advanced 
eggs, mates with that one first, and then with the others in succession. If, however, he is placed with only one female, and that one with very young eggs, he does not attempt to take her until the eggs are five or six days old, and neither would the female permit herself to be carried by him till then. We have a few records of a male carrying a female for this length of time, eight or nine days before the young are extruded from the pouch, but he will only do it when there is no riper female present. The relative size of the male and female in mating does not seem of much importance; at times a big male will take a very small female, and vice versa.

We have watched the whole process of the moulting of the female, followed by fertilization and oviposition, and find that it is practically the same in our species as in Gammarus pulex, as described by Della Valle (1).

In the case watched, the last young one of the previous brood was extruded at 2 p.m. (December 14th, 1912), while the male was holding the female. They swam about together afterwards, stopping occasionally to seize and eat pieces of ulva.

A periodic convulsive movement on the part of the female, increasing in frequency and violence, led up to the casting of the skin at 7 p.m. the following day. Meanwhile the male employed not only the second gnathopods, but the first and second peraeopods as well in holding the female. At times the male arched himself, bringing the urosome up to rest against the fifth peraeon-segment of the female, and then suddenly straightened out, rasping the uropods along the female's cuticle. During the whole time the male kept the lower antennae bent over the head of the female, so touching both pairs of her antennae. About two hours before the moult the female commenced a series of violent rapid jerks, bringing the head and urosome together, and then straightening suddenly, at intervals stiffening the body in the form of a comma, with the head bent downwards, the body moving with a sort of convulsive tremor. Finally the male ceased swimming, and they both lay quiet, while the female, helped by the male, freed the head from the old cuticle with the gnathopods. This process and the ensuing rest occupied not more than five minutes. Then the male suddenly arched the body as before, and in straightening again pushed off the posterior portion of the moult with his uropods, assisted by the upward heaving of the female's body. He did not relinquish his hold for a moment. After moulting the female lay absolutely still, without even a movement of the pleopods, while the male kept up a steady current with his. In a few minutes they commenced to swim as before. 
About an hour and a quarter after the moulting the male began to turn the female round, and after several efforts he succeeded in getting into the position described by Della Valle. At 8.30 p.m. the first ejection of sperm into the pouch was effected in four or five spasmodic movements. After lying quiet in this position for a minute or so, the male resumed the dorsal clasp, but five minutes later the whole process was repeated. Once more after an interval the male resumed the original dorsal position and swam again. After another five minutes - at 8.40 p.m.- the female suddenly struggled free, and did not allow the male to carry her again, darting away if he approached. Just at the moment they separated the first egg was seen emerging from the aperture of the oviduct. The last egg passed from the ovaries exactly twenty-four minutes later, and the newly extruded mass hung in the pouch in spheroidal form, the eggs held together by a glutinous secretion. The number of eggs was forty.

In another case watched, a distinct oviduct was apparent during the passage of each egg from the ovary to the exterior. This was clearly distinguishable as a thin light line only during the actual extrusion of the egg. The eggs laid first were pushed forward in the pouch by the later ones, and it may be mentioned here that the front ones were seen to hatch first.

The female can moult alone after extruding a brood from the pouch, so the presence of a male is not imperative for the moult, but our experience agrees with Embody's, that eggs are never deposited unless a male is present. In the absence of a male the eggs develop enormously in the ovaries, and are separated by distinct spaces, as happens during the normal development in the pouch, but what ultimately becomes of them has not yet been traced.

We have tried several experiments to determine the extreme interval that can elapse between any given moult and the subsequent oviposition, and we find that on the third day oviposition is still possible. If a male is kept away for four days or more after the female's moult, no mating occurs until the fourteenth day, i.e. until the next period begins, and such mating is preceded by a second moult.

It is evident that in the female moulting is directly connected with mating. The animal of course increases in size also, but as the moults occur at fortnightly intervals this increase is too gradual to be noticed at the time. With the male, on the contrary, moulting appears to be purely a growth process. The moults are at long intervals, and the increase in size very noticeable. The oldest male we have, extruded June 19th, became sexually mature July 25th, and has only been observed to moult three times since, on Aug. 1, Sept. 4, and Nov. 5. 
The number of eggs in the broods we have counted varies between five and forty-four, about thirty being a fair average. The number seems to increase with age, as one would expect, e.g. one female increased the number gradually from eighteen to forty-four. The eggs when laid have the characteristic blackish-green colour of the ovary; about a week later they turn brown, then yellow, the body of the embryo being now distinctly visible. They are hatched about the twelfth to the fourteenth day, and the young are extruded from the pouch the day after. Discomfort will hasten the extrusion, e.g. irritation with a brush, lack of water, etc.

Our results show that the age of sexual maturity is from thirtysix days onward, but we are inclined to think the earlier age the more normal. Counting the time from oviposition, only fifty days, therefore, elapse between one generation and the next, and this period is probably less in the heat of summer. We have now (Jan. 2, 1913) after seven months, the young of the fifth generation.

\section{THE YOUNG.}

The young remain one day, or at the most two days, in the incubatory pouch after hatching. The four pairs of incubatory lamellae with their interlacing hairs form a continuous pouch except for a small aperture in front and one behind, where the lamellae are separated at the top by the width of the female's body. Through these apertures the young emerge, but the female can close the entrances at will by bending down her projecting mouth-parts, and by lateral compression with her gnathopods and peraeopods. At times some of the young come halfway out, others again creep right out at the back and crawl along her ventral surface between the bases of her hinder peraeopods, then suddenly double back and re-enter the pouch. But if once they get outside the peraeopods, the swirl set up by beating pleopods prevents their ever re-entering. They are exceedingly active when inside, changing places continually; when they are once out they swim vigorously, and if they meet a piece of ulva or anything that can serve as shelter they climb in and hide themselves.

We have noticed an occasional female with red eyes instead of black, among the adults. A small proportion of the newly hatched young also have red eyes, the rest of their colouring being normal.

We have been puzzled by a great difference in size among the individuals in any given brood. Sometimes this is apparent when they are first extruded, at other times some gain enormously in size 
while growing as compared with the others, and finally some members of a brood become sexually mature much earlier than others. It may be simply that the weaklings lag behind, but as the male and female differ so much in size at sexual maturity it may perhaps be a sexual distinction. The results of our experiments may clear this point later.

We have isolated 130 newly hatched young from different broods, and are collecting and numbering the moults as they occur. We hope when they attain sexual maturity to be able to trace back in the moults the changes undergone, and the sexual distinctions if any. Certainly the last moult before maturity shows sexual differentiation, for the female already has the incubatory lamellae present, though only partially developed, and the male has a few of the coiled sensory hairs on the antennae, telson, etc.

The time taken in the moulting of the young appears to be much shorter than with the adult. For a few days previous they are less active than usual, and a flocculent sediment is noticed in the bottom of the bowl. This, we think, is the secretion, probably lubricative, of which a copious flow precedes ecdysis, oozing from between the terga, and from all the joints of the antennae, the peraeopods, etc. Della Valle (1, p. 111) refers to this in describing the moulting of the female. Several young have been watched moulting; they used their anterior appendages in loosening the old cuticle of the head, but the whole process, pulling off the head covering and slipping out of the posterior portion of the cuticle, only occupied three or four seconds.

The first moult seems to be the most critical; in one brood fifteen out of thirty-two died during the first moult. Afterwards the mortality is comparatively small. Where the period between moults has been longer than normal, the individual is undersized and evidently weakly, in many cases not surviving the next ecdysis. Below are tabulated side by side the rate at which two broods moulted, kept under exactly the same conditions in the cold room. The right-hand table refers to a brood seven days younger than the other, and it will be seen that the rate of development was quicker in the younger brood. Number $d$ in Brood I was much larger than the others when hatched, number $k$ much smaller. This one did not grow perceptibly after its second moult, and died seventeen days later in the effort to moult again. Number $e$ did not grow much after the second moult, and died just after its fourth moult. Number $i$ took the longest time yet recorded for a third moult-twenty-six days; it is an exceedingly small specimen, and had great trouble in getting rid of the old cuticle. 


\section{BROOD I.}

Extruded 5.11.1912.

\begin{tabular}{c|c|c|c|c|c|c}
\hline \multicolumn{8}{c}{ Period in Days Between Moults. } \\
\hline & $\begin{array}{c}\text { Moult } \\
1 .\end{array}$ & $\begin{array}{c}\text { Moult } \\
2 .\end{array}$ & $\begin{array}{c}\text { Moult } \\
3 .\end{array}$ & $\begin{array}{c}\text { Moult } \\
4 .\end{array}$ & $\begin{array}{c}\text { Moult } \\
5 .\end{array}$ & $\begin{array}{c}\text { Moult } \\
6 .\end{array}$ \\
\hline$a$ & 8 & 10 & 14 & 22 & 13 & 18 \\
$b$ & 8 & 11 & 17 & 12 & 15 & 18 \\
$c$ & 9 & 10 & 15 & 11 & 14 & 16 \\
$d$ & 9 & 13 & 15 & 12 & 16 & 17 \\
$e$ & 9 & 13 & 18 & 12 died directly after moult. \\
$f$ & 10 & 10 & 14 & 8 & 11 & 14 \\
$g$ & 10 & 10 & 15 & 14 & 14 & \\
$h$ & 10 & 10 & 17 & 10 & 14 & 16 \\
$i$ & 11 & 10 & 26 & 10 died in moulting. \\
$j$ & 11 & 11 & 14 & 16 & 11 & 15 \\
$k$ & 11 & 11 & 17 died in moulting. & \\
$l$ & 11 & 11 dead two days later. & \\
$m$ & 11 & 11 dead two days later. & \\
$n$ & 12 & 12 dead two days later. & \\
$o$ & 13 & 9 & 13 & 27 died in moulting. \\
$p$ & 13 & 12 & 13 & 9 & 13 & 20 \\
$q$ & 13 & 14 & died in moulting. \\
\hline
\end{tabular}

\section{BROOD II.}

Extruded 12.11.1912.

\begin{tabular}{|c|c|c|c|c|c|c|}
\hline \multicolumn{7}{|c|}{ Period in Days Between Moults. } \\
\hline & $\begin{array}{c}\text { Moult } \\
1 .\end{array}$ & $\begin{array}{c}\text { Moult } \\
2 .\end{array}$ & $\begin{array}{c}\text { Moult } \\
3 .\end{array}$ & $\begin{array}{c}\text { Moult } \\
4 .\end{array}$ & $\begin{array}{c}\text { Moult } \\
5 .\end{array}$ & $\begin{array}{c}\text { Moult } \\
6 .\end{array}$ \\
\hline$a$ & 7 & 9 & 11 & 8 & 10 & 13 \\
\hline$b$ & 7 & 9 & 12 & 23 & 15 & 23 \\
\hline$c$ & 7 & 9 & 13 & 12 & 12 & 13 \\
\hline$d$ & 8 & 8 & 11 & 10 & \multicolumn{2}{|c|}{13 died in moulting. } \\
\hline$e$ & 8 & 9 & 11 & 9 & \multicolumn{2}{|c|}{10 died directly after moult. } \\
\hline$f$ & 8 & 9 & 11 & 15 & & 17 \\
\hline$g$ & 8 & 10 & 11 & 22 & \multicolumn{2}{|c|}{10 died in moultinot } \\
\hline$h$ & 8 & 10 & 12 & 12 & \multicolumn{2}{|c|}{$12 \mid 16$} \\
\hline$i$ & 8 & 14 & \multicolumn{4}{|c|}{10 dead nine days later. Very small. } \\
\hline & 8 & 14 & 11 & 11 & \multirow{2}{*}{\multicolumn{2}{|c|}{8 died in moulting. }} \\
\hline & 8 & 14 & 15 & $15 \mathrm{di}$ & & \\
\hline$l$ & 8 & \multicolumn{5}{|c|}{16 died during moult. } \\
\hline$m$ & 9 & 11 & 11 & 9 & 11 & 11 \\
\hline$n$ & 9 & 11 & 12 & 9 & 17 & 19 \\
\hline$o$ & 9 & 13 & 8 & 9 & & 11 \\
\hline J' & 9 & 13 & 12 & 11 & \multicolumn{2}{|c|}{11 very small one. } \\
\hline$q$ & 10 & 13 & 9 & 24 & \multicolumn{2}{|c|}{14} \\
\hline$r$ & 11 & 15 & \multicolumn{4}{|c|}{15 died during moult. } \\
\hline$s$ & 13 & 13 & 9 & 10 & \multicolumn{2}{|c|}{13 died in moulting. } \\
\hline
\end{tabular}


Another brood kept in the Laboratory gives a record of four moults in twenty-eight days. As contrasted with the two broods tabulated above, the period between the moults was much less, due no doubt to the higher temperature. Another instance is the "control brood" for Brood II, which was kept in the warm Laboratory; they were one day ahead of Brood II in the first moult and seven days ahead at the second moult.

\section{EXPERIMENTS IN VARYING THE SALINITY.}

Great variations in the salinity of the water can be endured by this species, but too sudden a change tries them severely. We have made some experiments with large adults. In one instance a male and a female were taken from the brackish water and put into fresh water on July 24th; two days later the female died, the male survived till the seventh day. Again, on July 24th, a male carrying a female was put into sea-water; they both moulted, and five days later were separate, but no eggs were produced. On August 3rd the male was again carrying the female, and on the 7th she moulted again, and again they were separate and no eggs present. On August 21st they were again paired, and on the 24th another moult was found, and the female was dead. The male died on the $26 \mathrm{th}$, so he had lived thirtythree days and she thirty-one. Evidently the sexual impulse was still there, but the power to produce was affected. In a third case, two halfgrown females were put straight into sea-water. One had very young eggs, which were soon thrown off; the other had two partly hatched eggs, which hatched and were extruded four days later. The two females are still alive, a month later, and their ovaries are much enlarged. The extruded young are swimming about in the sea-water.

Similar experiments just commenced with newly hatched broods promise some interesting results. They show that the first moult is critical; if that be survived they continue to flourish, but the period between moults is much longer than normal. One brood of seven $G$. chevreuxi were put into fresh water; they took from eighteen to twenty-one days to reach the first moult, and all died, either in moulting or directly after. Some nine $G$. pulex put straight into brackish water all accomplished their first moult safely, but took thirteen to fifteen days instead of seven to reach it; nine others of the same brood put into water onethird brackish to two-thirds fresh took nine days to this moult.

Finding the sudden change too drastic, a number varying in size were put on September 9th into two bell-jars. Small quantities of fresh water have been added to the one from time to time at a few 
days' interval, so that now the water is fresh. Although the original large adults have disappeared, we still have breeding pairs mixed with their own progeny in this jar. To the individuals in the second belljar small quantities of sea-water have similarly been added from time to time, and the water is now full-strength sea-water. The large adults died off in this case also, but their numerous progeny are flourishing and breeding.

The papers referred to above are:-

1. 1889. Della Valle, A. "Deposizione, fecondazione, e segmentazione delle uova del Gammarus pulex." Atti. Soc. Nat. Modena. Ser. III, Vol. VIII.

2. 1912. Емворy, G. C. "A Preliminary Study of the Distribution, Food, and Reproductive Capacity of some Fresh-water Amphipods." Internat. Revue, Leipzig, 1912.

3. 1903. Holmes, S. J. "Sex Recognition among Amphipods." Biol. Bull., V.

4. 1912. Sexton, E. W. "Some Brackish-water Amphipoda, etc." Proc. Zool. Soc., September, 1912. 